University of Rhode Island

DigitalCommons@URI

Open Access Master's Theses

1977

\title{
The Object of Signs in Charles S. Peirce's Semiotic Theory
}

William W. West

University of Rhode Island

Follow this and additional works at: https://digitalcommons.uri.edu/theses

\section{Recommended Citation}

West, William W., "The Object of Signs in Charles S. Peirce's Semiotic Theory" (1977). Open Access

Master's Theses. Paper 1559.

https://digitalcommons.uri.edu/theses/1559

This Thesis is brought to you for free and open access by DigitalCommons@URI. It has been accepted for inclusion in Open Access Master's Theses by an authorized administrator of DigitalCommons@URI. For more information, please contact digitalcommons-group@uri.edu. 
THE OBJECT OF SIGNS IN

CHARLES S. PEIRCE'S SEMIOTIC THEORY

OF

WILLIAM W. WEST

THESIS SUBMITTED IN PARTIAL FULFILLMENT OF THE REQUIREMENTS FOR THE DEGREE OF

MASTER OF ARTS

IN

PHILOSOPHY

UNIVERSITY OF RHODE ISLAND

1977 
TABLE OF CONTENTS

Page

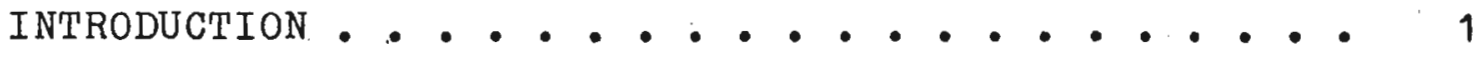
Chapter

I THE CATEGORIES • . . . . . . . . . . 4

II SIGNS EXPLAINED . . . . ... . . . . . 8

The First Trichotomy: The Sign Itself .... 15

Qualisign . ... . . . . . . 15

Sinsign . . . . . . . . . . 16

Legisign . . . . . . . . . . 17

The Second Trichotomy: The Sign-object

Relation ........... 18

Icon ........... 19

Index . . . . . . . . . . . 24

Symbol .. . . . . . . . . . . 28

The Third Trichotomy: How the Interpretant

Represents the object ... . . . . 32

Rheme . . . . . . . . . . 32

Dicisign . . • . . . . . . . 32

Argument . . . . . . . . . . 33

Dynamical objects, Immediate objects, $\because \ldots .$.

Dynamical Interpretants, Immediate

Interpretants, Final Interpretants . . 35

Immediate object, Dynamical object. . 35

Immediate, Dynamical and Final

Interpretant . . . . . . . 37

III WHAT IS THE OBJECT OF A SIGN? . . . . . 41 
Page

CONCLUSION ........................ 61 NOTES ....................... 66 
dynamical-final interpretant distinction is also attempted in this ohapter.

In chapter III the question of the object of signs is taken up in some detail. Here it is argued that every sign has an object when it is actually functioning as a sign. In this regard much emphasis is put on the role of context in determining the object of a given sign. The distinction between the immediate and dynamical object is developed in greater detail and it is suggested that this distinction might be helpful in deciding whether or not Peirce thought all things are signs.

In the conclusion a summary of the arguments for the necessity of a convention for all signs and the intentionality of all signs is given and some other questions in sign theory are suggested.

A bibliography is appended to the end of the thesis. 


\section{INTRODUCTION}

This thesis deals with Charles S. Peirce's semiotic theory, with concentration on the questions of the conventionality and intentionality of signs. Do all signs require conventions and do 2.11 signs refer to an object? It will be my contention that all signs do require a convention in order to signify and that all signs do refer to an object. In this regard, it will be helpful to explain what I mean by a convention and what I mean by "refer to".

I would explain the idea of convention in terms of decision and designation. A convention is a decision on the part of some intelligience to designate or accept one thing as a sign of some other thing. This convention may be public or private, shared or not shared; but in any case it is required in the making of a sign, and before any particular sign can signify for any particular individual, that individual must be aware of the convention which is necessary in making that sign a sign. If we were to phrase this in more traditional terms, we might say a convention is an agreement, compact or contract. of an intelligience with itself to regard such and such as a sign of such and such.

By the power to "refer to", I mean the power of a 
sign to direct attention or thought toward something. Signs always point to something. This thing is its object. It is my contention that just as thought is always thought of something, a sign is always a sign of something.

I have used Douglas Greenlee's Peirce's Concept of Sign as a major secondary source and foil to Peirce's theory, since his is the only comprehensive study of Pelrce's semiotic dealing with these issues.

My hope is that this thesis will succeed in marking out the essential features of a sign and stimulate thought on the many other issues in semiotic theory.

Note: All references to Peirce's writings refer to the Collected Papers (Cambridge, Mass.: The Belknap Press of Harvard University Press, 1960.). Volumes I-VI are edited by Charles Hartshorne and Paul Weiss. Volumes VII-VIII are edited by Arthur W. Burks. The references are usually indicated within parentheses "()". The number before the decimal point indicates the volume number and the number after the decimal point indicates the paragraph number. For instance (2.236) would indicate volume II, paragraph 236 of the Collected Papers. The squared off brackets "[]" sometimes found in the course of quotes from Peirce in this thesis indicate words added either by the editors of the collected papers or by the writer of this thesis. To distinguish the source of the brackets, initials are

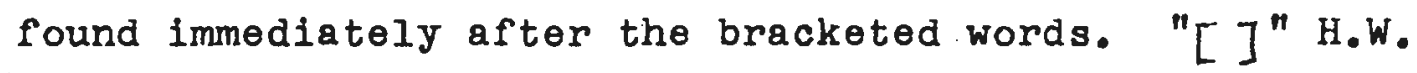


indicates a bracket inserted by Hartshorne and Weiss. "[ ]" A.B. Indicates a bracket inserted by Arthur Burks. "[]"W.W. indicates a bracket inserted by the writer of this thesis. 
Chapter' I

THE CATEGORIES

Like all detailed studies of Charles S. Peirce's semiotic theory, this one will start with an account of his all pervasive triadic, categorial scheme. Peirce, in an article subtitled "The author's response to the anticipated suspicion that he attaches a superstitious or fanciful importance to the number three, and forces divisions to a Procrustian bed of trichotomy", defends himself from the accusation that he suffers from a mental disorder that might be called triadomany. $(1.570)$ Peirce feels that the triadic division of being as well as the further numerous triadic classifications and subdivisions of various subjects is necessary and unavoidable. This is just the way things are, and the three categories are exhaustive of reality. Since Peirce applies these categories to virtually every area of his philosophy, both as a device of ontological division and as a tool of analysis, it is a prerequisite of any study of Peirce to have a working knowledge of these three catefories. What then, are these three categories? They are named quite unassumingly firstness, secondness and thirdness.

Firstness is described by Peirce in various places as mere possibility (1.304) or anything describable with- 
out contradictions or unanalyzed immediate foeling (1.310). Qualities are the denizens of this category.

But I (Peirce) mean the qualities themselves which, in themselves, are mere maybes, not necessarily realized . . . That mere quality, or suchness, is not in itself an occurence, as seeing a red object is . . . Its only being consists in the fact that there might be such a peculiar, positive, suchness in a phaneron. When I say it is a quality I do not mean that it inheres in a subject. $(1.304)$

Firstness then, is pure possibility or quality or unanalyzed feeling. Peirce gives the example of a man just awaking from sleep and experiencing the undifferentiated blanket of qualities in that split second before he assigns each quality to a subject and structures the room. At that moment he is disoriented, and all there is is a myriad of undifferentiated qualitios or the qualities themselves. (8.346). But "a quality or feeling can be imagined without any occurance... its mere maybelng gets along without any realization at all". $(1.304)$

Secondness is the category of hecceity or thisness, of spatio-temporal objects or events. It is what "happens to be"; whatever is real, in the sense of having the character of brute force. "Generally speaking genuine secondness consists in one thing acting upon another brute action." Secondness, then, is the category of dyadic relations and here and now brute existence.

Thirdness is the category of would-bes. That 1s, it is not about "what actually occurs, but of what would, in the long run, occur under certain circumstances". (6.328) The category of thirdness contains laws, habits of nature, 
or generals. These are the laws or habits that guide the relations of secondness.

Now what would-be can, it is true, only be learned through observation of what happens to be; but nevertholess no collection of happenings can constitute one trillionth of one percent of what might be, and would be under supposable conditions. (6.328)

Although Peirce generally associates universalo with generals, there are passages which indicate that perhaps they should be kept separate $(5.343,2.324)$; and the examples Peirce gives of universals (redness, qualities, relations etc.) Indicate that universals are might-bes or firstnesses and generals as laws about what would-bes are thirdnesses. On this interpretation universals need not be instantiated since they are possibles, whereas generals must be instantiated in order to have being - or truly be said to be what they are. Peirce says that a true general cannot have any being unless there is some prospect of it being embodied in a fact, which, of course, is not a law. $(1.304)$

The three categories might be briefly identified as follows. Firstness is the category of possibility. Secondness the category of brute actuality. Thirdness is the category of law or generality. In various places Peirce makes it clear that Firstness and Thirdness are not to be considered lifeless things merely because they do not have the mode of existence of Hecceity. (3.460, 2.222, 6.455, 1.26, 5.453 et al) I make this point in order that as we later investigate the question of the object of signs, we 
keep in mind that we neodn't look solely to the category of secondness or actuality. Signs will often refer to things of firstness and thirdness. It is also possible that signs will point to purely fictive objects.

The above should give an adequate picture of Peirce's categories and should render Peirce's semiotic division somewhat more intelligible. One more point should be made before we attempt an explanation of Peirce's semiotio. That point concerns Peirce's use of the categories. Peirce seems to use his categories in two ways. One way is as a basis of division according to the mode of being of something. The other way is as a tool of analysis to identify certain characteristics, features or factors of a given subject matter. Douglas Greenlee calls these the hypostatic and factorial versions of the categories, respectively. And I think that this distinction of Greenlee's is worthwhile to bear in mind. Greenlee may make more of this distinction than is warranted, since he feels that Peirce himself was not fully aware of it and so was led to some confusion by it. This is an issue I will take up later. For now I think it is enough to note that there is something of this sort going on. 
Chapter. II

\section{SIGNS EXPLAINED}

After spending some time trying to understand Peirce's semiotic theory one becomes aware of certain problems. Peirce's work with signs was pioneering work. Much of his ciassification was tentative and experimental. This often manifested itself in a continual changing and rearranging of the names and classes of various signs. For instance, as late as 1908 in a letter to Lady Welby we find Peirce asking if she can "suggest a really good name" for a "possible" sign, which Peirce had already alternately named on previous occasions a "tone", a "tynge", a "mark", a "potisign" and a "qualisign". Sometimes Peirce would make a distinction, for example, between a representamen and a sign, and then later all but ignore the distinction and use the words interchangeably. When Peirce originally began his analysis of signs, he only distinguished the sign, the object, and the interpretant and so was led to only ten classes of signs. Later, however, Peirce further distinguished two different types of objects and three different types of interpretants. This led him to suppose that there were possibly 59,049 classes of signs. He did not think there were actually this many, but he did think there were 59,049 very difficult questions to consider as to 
which ones would be actual classes. Pefrce usually assumed this number could be reduced to 66 classes, but is never sure of this. And of these 66, only a handful were examined in any detail. If one adds to these problems the fact that his sign theory is scattered throughout his writings in various papers and fragments and the fact that it is nowhere brought together in one work, it is clear that the task of determining just exactly what Peirce meant to say on a given aspect of semiotic theory is by no means easy. One should also not be surprised to find some contradictions among Peirce's writings. This is the impression one is left with as the study first begins, but upon deeper analysis some of the seeming contradictions begin to resolve themselves. I stress the word some, since not all can be resolved and some seem unresolvable. All this is only by way of demonstrating the complexity of Peirce's work in the field of semiotics. The complexity of semiotic theory itself, perhaps, goes much deeper.

One of the problems this thesis will attempt to deal with is the problem of reference of signs. In this regard an important point to bear in mind is this: signs are rarely, if ever, used in isolation. In other words, signs are virtually always set in a context of other signs or in the context of a given situation, which situation itself becomes a sign of how a given sign is to be interpreted. The object of a given sign can therefore change depending on the sign's context. For example, any de- 
monstrative pronoun certainly has its object contextually determined. But, for instance, the word "ground" and the word "arms" each has its own separate object if considered individually, but taken together they form a command i.e. "Ground arms!", which has its own object. Taking them individually does not seem to capture exactly. What the object of each is in this context.

Another feature of signs which may cause some problems is the way in which their classification may change depending on the perspective of the classifier. For instanco, a footprint in the sand on a desert island could be classed as an index, since. it has real relation to its object which is in this case the man who made it; or it could be classed as an icon since it bears a resemblance to at least a part of a man. This type of elusiveness of signs in their character and meaning may cause some confusion in trying to interpret Peirce unless we keep in mind that an analysis. of signs can only consider one perspective at a time. Therefore it is helpful to view Peirce's examples from the perspective that Peirce is using at the time, since pure examples of hif classes are seldom available. With these considerations in mind, I'll proceed with an explication of Peirce's sign theory.

Peirce defines a sign many times in his Collected Papers. $\quad(1.339,1.438,2.228,2.274,2.303,4.531,6.347$, $8.177,8.179$, et.al.) A typical definition of a sign is as follows. 
A sign, or representamen; is a first which stands in such a genuine triadic relation to a second, called its object, as to be capable of determining a third called its interpretant to assume the same triadic relation to its object in which it stands itself to the same object. $(2.274)$

Another definition of a sign is as:

- . anything which determines something elsel (its interpretant) to refer to an object to which itself refers (its object) in the same way, the interpretant becoming in turn a sign and so on ad infinitum. (2.303)

And another definition is made as follows:

- . anything which being determined by an object determines an interpretation to determination, through it by the same object . . every sign is determined by its object, either first by partaking in the characters of the object, when I call the sign an icon;: secondly by being really and in its individual existence connected with the indiviual object, when I call the sign an index; thirdly by more or less approximate certainty that it will be interpreted as denoting the object, inconsequence of a habit (which term I use as including a natural disposition), when I call the sign a symbol. (4.531)

The sign relation is an irreducubly triadic relation and is therefore relegated to the category of thirdnoss. Why then does Peirce make a definition of signs in terms of firsts, seconds and thirds? The answer is that while ithe: mode of being of the sign relation is that of thirdness, in analyzing the sign relation the three factors of the sign relation are firsts, seconds, and thirds in respect to each other, as Peirce points out:

- - the first, the second and the third are all three of the nature of thirds, or thought while in respect to one another they are first, second and third. The first is thought in its capacity as mere possibility; that 1s, mere mind capable of thinking, or a mere vague idea. The second is thought playing the role of secondnness, or event. That is it is of the general nature of experience or information. The third is thought in its role of governing secondness. It brings the information 
into the mind, or determines the idea nnd gives it body. It is informing thought, or cognition. But take away the psychological or accidental human element, and in this genuine thirdness we see the operation of a sign. $(1.537)$

The sign itself is called a first in relation to the object and interpretant because the sign as uninterpreted is capable of a number of possible interpretations and possibility is, as we have already shown the predominent characteristic of firstness. The object is secondness since it is the part of the sign relation which causally (using causally loosely) determines the sign and mediately the interpretant. As for the interpretant, Greenlee feels it is to be seen as a third because interpretation always involves interpretation which is general. But he then admits that such an explanation is not without problems since, as he correctly points out, Peirce allows for interpretants. which are particular rather than general. But it may be better to view the interpretant in terms of a habit or law. of interpretation. That is a habit of interpreting the sign. in a certain way on the part of the interpreter. Thus the problem of a particular interpretant (such as at a given command performing a particular action) can be avoided by viewing this as an instantiation of a general habit.

So the sign has a character of possibility awaiting interpretation. The object has the charcter of actuality in that it is the causally determining factor in the sign relation. And the interpretant has the charcter of generality either as interpreting thought or as instantiated 
habit. But it must be remembered that this is just an analysis of the triadic relation using the categories as a means for bringing out the prominent features of the genuinely and irreducibly triadic sign relation, which properly belongs to the category of thirdness. It should also be remembered that the sign vehicle, the object, and interpretants themselves may have a mode of being in any of the categories. For instance, a sign may be an actual sign or second as any actual written or spoken sign is, or a general as the sign is without instantiation. This distinction is the type-token distinction. That is, as Peirce puts it:

There will be ordinarily about twenty "the's" on a page, and of course they count as twenty words. In another sense of the word "word", however, there is but one word "the" in the English language; and it is impossible that this word should lie visibly on a page or be heard in any voice, for the reason that it is not a single thing or single event. It does not exist. It only determines things that do exist. Such a de: finitely significant form, I propose to term a type. A single event which happens once and whose identity is limited to that one happening or a single object or thing which is in some single place at any one instant of time, such event or thing being significant only as occurring just when and where it does such as this or that word on a single page of a single copy of a book, I will venture to call a token. $(4.537)$

An object, too, as mentioned earlier may be of any of the three modes of being. For instance an object may be a specific individual person such as Napolean or a general thing such as mankind. An interpretant may be an action such as a soldier's actual grounding of arms upon the command to "Ground arms!", or it may be a general thought or idea such as the concept of the act of giving. The sign relation, then, is a third with its constituents capable 
of analysis in terms of first, second and thirds.

The sign relation also involves an infinite series of interpretants. Since each interpretant is itself a sign, it must have its own interpretant and so on ad infinitum. The infinite regress (or progress, depending on your perspective) seems to present some problems. Does this mean a sign is never fully interpreted, or that once a sign is interpreted must it continue to be interpreted in infinite succession? Briefly, the answer is no to both questions. Peirce points out that "if the series is broken off, the sign, insofar, falls short of the perfect significant character. It is not necessary that the interpretant should actually exist. A being in futuro will suffice." (2.92) So the way to avoid the problems of an infinite series is to describe the series as a potential rather than an actual one. In other words, every sign has a power to determine an interpretant and that interpretant, once determined, becomes a sign which also has a power to determine a future interpretant. I will have more to say on this "power" to determine interpretants when we get into the section on interpretants.

Having said this much by way of general explanation of Peirce's definition of and theory of signs, I propose to take each member of the triadic relation and investigate it separately. Peirce has made three divisions of trichotomies of signs. The first is based on how the sign is in itself. The second is made according to the relation of the sign to 
its object and the third is made according to how the interpretant represents the sign. An investigation of those three trichotomies, then, should yield some understanding of the three constituents of the sign relation. The first will tell us about the sign itself, the second will tell us about the object and the third will tell us about the interpretant. As mentioned earlier, Peirce later outlined ten trichotomies after he developed a distinction between an immediate object and a dynamical object, and a distinction between an immedate, dynamical and final interpretant. The analysis of the other seven trichotomies was barely even started, but the new distinctions among objects and interpretants are important to an understanding of Peirce. I will take up the explanation of these distinctions after an explanation of the three trichotomies.

\section{The First Trichotomy: The Sign Itself}

Peirce explains the first trichotomy as follows: "According to the first division a sign may be termed: a qualisign, a sinsign, or a legisign." (2.244) Qualisign: "A qualisign is a quality which is a sign. It cannot actually act as a sign until it is embodied, but the embodiment has nothing to do with its character as a sign." (2.244) An example of this type of sign would perhaps be the quality red which has come to indicate danger in various mediums. The quality red may be a sign to stop if its used in : a traffic light or it may indicate danger as is sometimes the case with certain pieces of medical equipment. 
The sign itself is a quality. Of course there are no pure qualisigns since qualities taken universally are only possibles. Any embodiment of a quality necessarily makes it no longer a possible. But the point is that it is the quality, not the actual embodiment of the quality, which is called the sign and this gives it its character of a qualisign.

Sinsign: A sinsign (where the syllable sin is taken as meaning "being only once", as in single, simple, Latin semel etc.) is an actual existent thing or event which is a sign. It can only be so through its qualities; so it involves a qualisign or rather, several qualisigns. (2.245)

Sinsigns are similar to tokens in one respect, that is, all tokens are sinsigns in that they are the actual here and now written or spoken word. For that matter the example of the red light is a sinsign in any instance that it is $n$ actualized. However, it is not quite clear that every sinsign is a token since in this trichotomy the basis of distinction seems to be the character of the sign which makes it significant. So fust as it was the possible quality red, as opposed to any particular actualization of red which gave the red light its significative power, one might argue that a sign should not be put in the class of sinsigns merely because of its being an actual here and now sign (as any ": actual instance of a written or spoken word.is), but rather a sign should be classes as a sinsign only if it is a single or uniquely different ovent which is significant. This typo of event would presumably be of the nature of an omen or 
some natural event that is a sign. In other words it is the event itself rather than the event of the instantiation of a general sign which gives the sign (which could properly be put in the category of sinsigns) its character as a sign. If this analysis is correct then the identification of a sinsign and token which Peirce seems to make later may be improper. Peirce, however, does not seem to make this confusion in the section from $2.243-2.246$ where he develops this trichotomy, as he says in 2.246, "The replica is a sinsign ... But these are not ordinary sinsigns, such as are peculiar occurrences that are regarded as significant."

Legisign: A legisign is a law that is a sign. This law is usually established by men. Every conventional sign is a legisign but not conversely. It is not a single object, but a general type which it has been agreed shall be significant. Every logisign signifies through an instance of its application, which may be termed a replica of it . . the replica (would not be) significant if it were not for the law which renders it so. $(2.246)$

A legisign, then, is a type. That is, it is a word or sign taken generally. The word "bird" is not anywhere written or spoken.but it is a general type which we agree will be significative whenever it is actually written or spoken. A legisign, according to Peirce, is not always a conventional sign. For instance, a symptom of a disease is a natural sign of that particular disease. This symptom, if taken generally, would be a legisign or type, i.e. the symptom is not any particular instance of the symptom in a particular person, but the symptom in general. But, there is some 
question on this point. Greenlee thinks that not only all legisigns require a convention, but also that all signs require a convention. 7 That is, every sign requires a convention by which the sign is made significative. I think that Greenlee is right on this point. However full discussion of it is more properly left to the second trichotomy of signs. I raise it here because we should not take it as granted that not all signs require a convention. In closing our discussion of this section it is important to note that we class the sign itself according to the characteristic of a sign which makes it significative. That is, the signification may be due to a possible quality (qualisign) or an actual existent or event (sinsign) or a general law (legisign). But nelther a qualisign or a legisign can actually function as a sign unless they are' embodied in an actual sign or sinsign. And a sinsign requires qualisigns or qualities in order to acquire a distinctive character and so function as a sinsign. So although each has a prominent characteristic which serves as the characteristic of division, they require the characteristics of each trichotomy in order to actually function as a sign.

The Second Trichotomy: The Sign-Object Relation

Peirce felt that this trichotomy was the most important. This is the one he most often refers to when making a brief explanation of sign theory. The main reason for emphasis on this trichotomy can be found in the "fact that he considered his work on signs to be foundational to 
logic. And logic is concerned with the relation of a proposition to its object or whether or not the proposition represents its object correctly.

Icon: At any rate, according to the second trichotomy a sign may be termed an icon, index, or a symbol. Peirce says that the "icon,is sign which refers to the object it denotes merely by virtue of characters of its own." (2.247)

It is important to note here that the basis of division for this trichotomy is the relation of sign to object. In the case of an icon the relation is one of resemblance. That is, it is the qualities posessed by the sign which are the same or similar (either substantively or structurally) to those of the object, which make it representative of the object. It is the similarity to the object which makes it fit to function as a sign of that object. The sign has these characteristics or qualities independently of the object. Obvious examples of iconic signs are maps, paintings, and photographs. Peirce says that the sign "stands for that object, not in all respects, but in reference to a sort of idea, which I have sometimes called the ground of the representamen." (2.228) The ground is an idea or pure absrtaction from the object in question. It is the relevant aspects or package of aspects of the object to which the sign refers. For example the sign, "John is big" refers to John but only in respect to the abstract idea of the bigness. But the ground of a sign can be taken in an even larger sense. In 2.228 Peirce goes on to explain what he 
considers the ground to be. The sign:

stands for that object, not in all respects, but in reference to a sort of idea. . "Idea" is here to be understood in a sort of Platonic sense, very familiar in everyday talk; I mean in the sense in which we say that one man catches another man's idea...."

In 1.551 Peirce speaks of the ground in terms of a pure abstraction. In this sense the ground, for instance, of the sign "bird" would be the abstract idea of a bird or the package of relevant aspects which a bird posesses. And when the word "bird" is used to stand for a particular bird, it stands for it not in all respects but in respect of this ground. Although this example does not apply directly to icons since "bird" is not an icon, it does illustrate the idea of the ground of signs. The ground is that aspect of the object which is represented to the interpreter by the sign.

With this in mind, Greenlee argues convincingly that a convention or rule of interpretation must establish. the ground of representation (and accordingly to signification) of the icon. ${ }^{8}$ The point is this: according to Greenlee,

It is not simply similarity, but similarity determined as resemblance which constitutes the ground of iconic signification.. . That is, since W.W. . . similaritios are not always rocognized and since objects similar to other objects do not always represent them iconically or through the similarity the obtains among them, a convention or rule must have been established to the effect that the sign should be interpreted to signify in a cegtain way, which is through some respect of resemblance.'

If this analysis by Greenlee is correct, then the icon is symbolic since the symbol, as we shall see later, is a sign 
which signifies by virtue of a law or convention.

Greenlee feels that Peirce was confused on this point. That is, that Peirce did not realize the application of the categories was analytic in regard to developing this trichotomy and that Peirce did not realize that all signs involve a convention, law, or habit which serve to designate them as signs in some respect. Further, Greenlee believes that Peirce thought that this second trichotomy represented different modes of being of signs rather than different factors of the sign situation. But it's not atiall clear that Peirce was confused on this point. For instance, Peirce speaks of the icon and index as being degenerate forms of the sign, which may indicate that he realized quite well that all signs are thirds and that the symbol is a genuine sign while the icon and index are merely degenerate forms of it. He says:

Genuine mediation is the character of a sign .. . signs have two degrees of degeneracy. A sign degenerate to a lesser degree, is an obsistent sign, or index, . which is a sign whose significance of its object is due to its having a genulne relation to that object irrespective of the interpretant... A sign degenerate to the greater degree is an originalian sign, or icon, which is a sign wose significant virtue is due simply to its quality... A genuine sign is a transuasional sign, or symbol, which is a sign which owes its signi-

: ftcant virtue to a character which can only be realized by the aid of its interpretant." (2.92)

I think passages like these are enough to indicate that Peirce was not confused about how he was using his categories. That is, ho was quito clear that all signs were thirds by virtue of their triadic nature and that the symbol was a genuine third while the icon and index were 
degenerate thirds. But it is a degeneracy of thirdness, not a difference in modes of being. I do not think that it is quite fair to say that peirce was confused because he did not generalize the conventionality of the symbol to icon and index. He may have been convinced that their significance did not come from a convention but as he says above from a qualitative aspect for the icon and a genuine relation to its object for the index.

I think the evidence indicates that Pelrce believed that not all signs were conventional. For example in 2.246 he says that "every conventional sign is a legisign but not conversely H.W.." And in 3.361 Peirce says that the relation of the object of an index and the index does not lie in a mental association. And that it signifies its object solely by virtue of being really connected with it. All natural signs and physical symptoms are of this nature according to Peirce, and once again they are called degenerate signs. But in 2.303 Peirce gives a standard definition of a sign, explaining how a sories of interpretants is produced and goes on to say that "no doubt intelligent consciousness must enter into the series." In numerous places Peirce says,"Nothing is a sign, unless it is interpreted as a sign." (2.307) or has the power to be interpreted as a sign. (1.542) Passages such as these give some indication that some kind of convention is involved in every sign, since a mental association may be construed as a convention. ${ }^{10}$ But this is far from strong evidence. 
If Pelrce believed that not all signs require some degree of convention, we can still disagree with him. It seems to me that nothing is automatically a sign. That is nothing is a sign merely by virtue of a genuine relation to its object or by virtue of its qualitative resemblance to an object. That which functions as a sign must have some designation of it. a sign. It is not meroly by virtue of its capacity to act as such, because anything whatsoever has this capacity; anything can possibly function as a sign, but not everything is a sign. 11

A sign is properly so called once it has the power to determine an interpretant. (1.542) Such a power, it seems to me, can only derive from some designation of a sign as a sign of a given thing, or a sign with a given meaning. In other words, a convention must be established which designates something as functioning in such and such a significative way. To say there are signs which have the power to produce interpretants without such convention would seem to destroy the essential thirdness of a sign. For if something produces an interpretant without a given mediating habit or convention, it seems to sink into a merely dyadic relation. We would not say that a knee jerk is the interpretant of the sharp tap by the doctor's hammer. ${ }^{12}$ Nor should we say that the interpreting of smoke as a sign of fire is an interpretation which does not involve a convention or prior designation of it as such a sign. For if it does not involve such a convention, how is it that we came to 
interpret smoke as a sign of fire? If we say that smoke causes one to think of fire then this is a dyadic relation and not a triadic sign. Even in the example of the sunflower Peirce is hesitant about calling this a sign or even a representamen.

A sign is a representamen with a mental interpretant. Possibly there may be representamens that are not signs. Thus, if a sunflower, inturning towards the sun, becomes by that very act fully capable, without further condition, of reproducing a sunflower which turns in precisely corresponding ways toward the sun, and of doing so with the same reproductive power, the sunflower would become a representamen of the sun. But thought is the chief, if not only mode of representation. $(2.274)$

Representation always involves thought, which is why things of nature in themselves have no power to signify unless thought by way of convention extends such power to them. But this is enough digression for now. I will return to this issue toward the end of this thesis. 13

Index: An index is a sign which refers to the object that it denotes by virtue of being really affected by that object. It can not therefore be a qualisign, because qualities are what they are independently of anything else. In so far as the index is affected by the object, it necessarily has some quality in common with the object. It does, therefore, involve a sort of icon, although an icon of a peculiar kind; and it is not mere resemblance of its object, even in these respects which make it a sign, but it is the actual modification of it by the object. $(2.248)$

In this definition the relation of sign to object which sets off the index is that of "being really affected by the object." obvious examples of such causal connectedness are a weathvane as a sign of the wind, a bullet hole as a sign of a gun, or a footprint as a sign of a foot, etc. A not so obvious example Peirce gives is a yardstick which might be thought 
of as an icon of a standard yard but is really an index of

it since it is physically related in that it is a copy made from a mold of the standard yard.

However, later redefinitions of the index tend to blur the obvious distinction. 14 For example, Peirce later defines the index as follows:

An index represents an object by virtue of its connection with it. It makes no difference whether the connection is natural, or artificial, or merely mental. There is, however, an important distinction between two classes of indices. Namely, some merely stand for things ot individual quasi-things with which the interpreting mind is already acquainted while others mau be used to ascertain facts. Of the former class which may be termed designations; personal demonstrative, and relative pronouns, proper names, the letters attached to a geometrical figure, and the ordinary letters of algebra are examples. They act to force attention to the things intended. Designations are absolutely indispensable for communication and thought. No assertion has any meaning unless there is some designation to show whether the universe of reality or what universe of fiction is referred to. The other class of indeces may be called reagents. Thus water placed in a vessel with a shaving of camphor thrown upon it will show whether the vessel is clean or not . - just as a designation can denote nothing unless the interpreting mind is already acquainted with the thing it denotes, so a reagent can indicate nothing unless the mind is already acquainted with its connection with the phenomenon it indicates. $(8.365 n)$

Elsewhere Peirce says:

The index asserts nothing! It only says, "There!". It takes hold of our eyes, as it were, and forcibly directs them to a particular object, and there it stops. Demonstrative and relative pronouns are merely pure indices because they denote things without describing them. (3.361)

Peirce says the pointing finger is the type of this class.

The problem that begins to arise is that the actual physical connection between index and object seems to be missing in some of the cases described. The best one can 
say for the pointing finger is that there is a connection of spatial contiquity. But in this case wo would certainly have to say that one must know what the significance of a pointing finger is before it can serve to point to anything. Have you ever tried to direct a baby's attention to something by pointing at it only to have the baby stare blankly at the tip of your finger? Personal pronouns and relative pronouns may also be said to be spatially related to their objects, but what about proper names which are now also included as indices? Often one cannot even assume a spatial connection. The best it does is to force the attention of thought on the idea of the particular person it denotes. The connection now between index and object may be natural, artificial or merely mental. It would seem that with this new redefinition, the feature which may distinguish an index from other signs is all but lost. For if every sign has an object and every sign directs attention to its object, should not every sign be considered an index, if indeed the connection may be artificial or merely mental as well as natural? I think we must answer jes. And I think Greenlee is quite right to point out this deterioration of the distinguishing feature of an index. ${ }^{15}$ The best one can say for Peirce's exposition of the index is that it may be desscriptive of an essential characteristic or power of a sign; that of forcing attention on an object or of the indexical quality of signs. The class of indices indicates the dynamic power of signs and so is at least akin to the original 
definition of index as having a real physical rolation to its object. The extent to which every sign has the dynamic power to force attention is the extent to which it is indexical in character.

But is the index also dependent on convention for its significative capacity, as the icon seemed to be? Here again I think that the most plausible answer is yes. Not only is a convention or habit of interpretation usually roquired to recognize the significance of an index (as for instance the pointing finger), but as Greenlee points out: - a pointing finger might be aimed at the surface of an object, or at the color, size, motion, glint and so on, or all of these. Some property or complex of properties must be stated or supposed. The provision for the condition is W.W. - the meaning of 16 reference to an index as a ground of representation. It is the selection of an aspect of the object in terms of a standpoint of representation. In short the standpoint from which the index represents an object is conditioned not only by dynamical connection, but also by a convention of interpretation appointing it as a sign and selecting 19 abstracting the relevant aspect of representation.

The point is that some sort of convention is required to distinguish exactly what the index is pointing to among the many possibilities.

The convention involved is a decision to appoint the index as representing its object in respect to certain aspects and limiting the possible scope of the index. Certainly there are many objects which are more naturally fit to serve as signs of other objects, but a recognition of this fact and designation of something as a sign is required in order to escape a mere dyadic relation. For example, 
there is nothing intrinsic to the nature of smoke to make one think of fire. If someone never saw smoke and fire together, there would be no reason to say smoke was a sign of fire. We do learn that fire causes smoke and so eastly determine that smoke is a sign of fire, but this is a mental connection and designation. Once this designation is made, smoke is a sign of fire. A limitation of the range of the smoke as a sign is also involved. It might have been designated a sign of heat or a sign of any combustible material (wood, coal, gas etc.). Eventually it may be a sign of all these things.

Symbol: A symbol is a representamen whose representative character consists precisely in its being a rule that will determine its interpretant. All words, sentences, books and other conventional signs are symbols. We speak of writing or pronouncing the word "man", but it is only a replica or embodiment of the word, that is pronounced or written. The word itself has ino extstence although it has real being, consisting in the fact that existents will conform to it. (2.292) A symbol is a sign which refers to the object that it denotes by virtue of a law, usually an association of general ideas, which operates to cause the symbol to be interpreted as referring to that object. (2.249)

The connection a symbol has to its object, then, is

a purely conventional one. A rule prescribes that things of such and such a type shall be interpreted as referring to such and such an object. ${ }^{18}$ And according to Peirce a "genuine symbol" is general and has a general meaning. For example, the word "bird" is a general type and has the general meaning or concept which the word "bird" signifies, i.e. a thing having wings, a body more or less covered with feathers, a beak; and usually able to fly, etc.. But Peirce 
also allows for two degenerate forms of symbol which can denote Individuals. There is the "singular symbol", "whose object is an existent individual and which signifies only such characters as that individual may realize." (2.293) An example of this would be the word "Charlemagne", which is itself general but refers to a particular individual, i.e. Charlemagne himself. And it is interesting to note that here a proper name is identified as a degenerate or singular symbol while in $8.365 \mathrm{n}$ a proper name is identified as an index. But this will present no problem if we affirm that all signs are symbolic and indexical in character and whether one should be classed as index or symbol depends on which aspect of a given sign we are considering at the moment. The other degenerate symbol. Peirce calls the "abstract symbol whose only object is a character". (2.293) Presumably an example of this type of symbol would be words such as "redness", "bigness", "hotness", etc. which name qualities or abstract properties. Peirce, consistent with his analysis of the categories, regards these not as general but as universal. This explains how a general symbol may refer to individuals, but the question might legitimately be put as to whether a symbol must itself be general as Peirce seems to imply in 2.292 above and in other places where he seoms to equate it with a legisign or type. (2.249) We do sometimes speak of individuals as symbols. For instance, Socrates, as a particular individual, is sometimes taken as symbolic of the Philosopher in general, or steadfast 
honesty, or scrupulous honor, or other superlative qualities. But we would hardly want to say that Socrates was a type when he was such a unique and special individual. Certainly he is a conventional symbol of these various things to certain people and not precisely an icon, or index, but he is also not a general type. He is a real individual. It may be wise to disregard the restriction of generality for symbols which belong to the ontological classification of signs of the first trichotomy and stick to the basis of division originally stated, that being the connection of sign to object, which in the case of symbol is a connection of thought and nothing more; a convention solely.

One should not identify the symbol with the legisign or type. But the general symbol does not indicate any particular thing; it denotes a kind of thing, according to Peirce. (2.301) The kind which Peirce is talking about is an idea or concept. He says ordinary words such as "give", "bird", and "marriage" are examples of symbols and also that they are applicable to "whatever may realize the idea connected with these words." These words do not show us birds or marriages or giving, but it is understood that we can imagine such things and have an adequate concept of such things, which we are able to associate with whatever realizes the idea connected with the words. (2.298) The object of a genuine symbol then, is an idea or concept; a concept of a bird, or a marriage or a giving, etc.. And this may even be the object of a singular symbol, 1.e. a concept of 
"Charlemagne" rather than Charlemagne himself is what the symbol refers to by itself, although ultimately it refers to the real individual Charlemagne. And the same may be said for the abstract symbol. This idea or concept is the ground of the symbol. So when a symbol is applied to a certain object, it refers to it not in all respects, but in respect to that ground.

Let me bring this discussion to a close with a summation. The basis of division of this trichotomy is that of relation of sign to object. Certainly the actual relation of icon to its object is a real physical connection. And the relation of symbol to object is a merely mental or conventional one. But these distinctions begin to blur once we realize that the icon and index both require a convention or mental connection in order for them to have any significative power. But this blurring is not solely the fault of this expanded concept of signs which Peirce may or may not have endorsed. It is also partly due to a certain expansion of the concept of some of the signs in his own thought. For instance, we saw in the discussion of index. that Peirce eventually disregarded the real physical or causal connection. Such an expansion takes in all signs, since all signs point to an object and it was this "pointing to" which eventually became the distinguishing feature of the index. Such a blurring of distinctions may not be helpful in preserving the categorial structure of Peirce's sign theory; but it does serve to bring out some of the important 
features of the sign relation. Two of the most important of these features are the conventionality and the intentionality of signs. The blurring of the distinctions by Peirce may be symptomatic of some confusion on his part, but it may also be symptomatic only of a realization on his part that a certain amount of blurring is unavoidable. Whether or not he was aware of the ontological (hypostatic) and analytic (factorial) distinction between the uses ho made of his categories, serves to bring out the key features of the sign relation.

The Third Trichotomy:

How the Interpretant Represents the Object

The third trichotomy is made according as the sign's interpretant represents it as a sign of possibility, a sign of fact or a sign of reason. And according to this division a sign may be a rheme, a dicent sign (or dicisign) or an argument.

Rheme: "A rhome is a sign which for its interpretant, is a sign of qualitative possibility, that is, is understood as representing such and such a kind of possible object."(2.250) Rhemes are the qualities attached to an object in a proposition, for instance in the proposition "John is a man and John is mortal", man and mortal are signs of the qualitative possibilities which are concepts that could be attached to John. They are rhemes because the interpretant represents them as signs of qualitative possibilities. Dicisign: A dicent sign (or dicisign) is a sign, which, for its interpretant is a sign of actual existence. It 
cannot therefore, be an icon, which affords no ground for an interpretation of it as referring to actual existence. A dicisign necessarily involves, as a part of it, a rheme, to describe the fact which it is interpreted as indicating. But this is a peculiar kind of rhome; and while it is essential to the dicisign, it by no means constitutes it." (2.251)

While a rheme is a term of a proposition or argument, the dicisign is the proposition itself. The terms are considered to be rhemes because they represent possibilities. A proposition is considered to be a dicisign because it represents (or purports to represent) an actual existent or fact. Peirce takes the position that "every kind of proposition is either meaningless or has a realsecondness as its object." (2.315) This is why the dicent sign is taken as referring to an actual existent.

Argument: an argument is a sign which for its interpretant is a sign of law. Or we may say that a rheme is a sign which is understood to represent its object in its characters merely; that a dicisign is a sign which is understood to represent its object in respect to actual existence; and an argument is a sign which is understood to represent its object in its chatacter as a sign. (2.252) The interpretant of an argument represents it as an instance of a general class of arguments, which class on the whole will always tend to the truth. It is this law, in some shape, which the argument urges; and this "urging" is the mode of representation proper to arguments. The argument must, therefore, be a symbol, or sign whose object is a general law or type. (2.253)

The interpretant of the argument as a law or general which indicates that all arguments of its type tend toward the truth. There is not much that needs to be said here except to note the categorial development of the division. The interprotant represents its object as either a possible existent, an actial existent or a general existent (law). The division also obviously parallels the parts of an 
or should be given up. They have been and are important in bringing out the features of the sign relation and of signs themselves and they may be useful in keeping these features and functions of signs clear. Ontological distinctions are not necessary. Since all signs have been put in the category of thirdness, the analytic distinctions based on the qualities and features which various signs exhibit should be enough for understanding different classes if signs. Indeed, we may find that the basic characteristic of signs, as opposed to sign vehicles, is of the nature of thought or generality.

Dynamical Objects, Immediate Objects, Dynamic Interpretants Immediate Interpretants, Final Interpretants

It is important in understanding Peirce and in understanding sign theory to get clear the distinctions Peirce makes between two types of objects and three types of interpretants.

Immediate Object, Dynamical Object: In his letters to Lady Welby and other correspondence, Peirce discusses this distinction. It is my contention that the immediate object is what Peirce described earlier as the ground and the dynamic object is that which the immediate object or ground is the ground of. Peirce says this:

As to the object, that may mean the object as cognized in the sign and therefore as idea, or it may be the object as it is regardless of any aspect of it, the object in such relations as unlimited and final study would show it to be. The former I call the immediate object, the latter the dynamical object. (8.183) We must distinguish between the immediate object - i.e. 
the object as represented in the sign, and the real (no, because perhaps the object is altogether fictive, I must choose a different term, therefore), say rather the dynamical object, . . Which it can only "indicate" and leave the interpreter to find out by "collateral experience". $(8.314)$. . a sign has two objects, its its object as it is represented and its object. in itself. $(8.333)$

If we compare these remarks with Peirce's earlier statements about a sign not referring to its object in all respects but in respect to a certain idea which ho called the ground, we can see the similarity of the immediate object and the ground. Both refer to the object as represented in a certain idea or abstract notion of the object and both refer to the object as being represented not in all respects but in reference to this sort of idea. The dynamical object is of course the same as the object itself or that which the ground represents. The reason this object is called dynamical is that according to Peirce it is the object which determines the signs and also mediately through the sign the interpretant. (see 8.179) It is this dynamic determination which gives the dynamical object its name. The dynamical object is also that with which previous experience is assumed by the sign or utterer of a sign.

The person who interprets a W.W. sentence (or any other sign whatsoever) must be determined by the object of it through collateral observation quite independently of the action of the sign. Otherwise he will not be determined to thought of that object. . a habit has been established in him by which that word calls up a varioty of attributes of a given object W.W.. (8.178)

The sign has no meaning unless you have had some previous acquaintence or knowledge of its object, whether it be by 
direct apprehension or by indirect description. It is through this previous acquaintence that the object determines the slgn and mediately the interpretant. The immediate object then is of the nature of a sign since all thought is in signs. The dynamical object may have the nature of any other category since it is possible for things of any category to be objects of signs. The dynamical object may be a sign since we can talk about signs or a real actual existent object or a general object such as a law or a universal object such as a quality. Immediate, Dynamical and Final Interpretant: This distinction is not quite as clearly made as the one between immediate and dynamical objects. And since it may not be as important to our later discussion, I will only deal with it briefly.

The three interpretants which a sign may have are: 1. its interpretant as represented or meant to be understood (this is the immediate interpretant); 2 . its interpretant as it is produced (this is the dynamical interpretant); 3. its interpretant in itself (this is the final interpretant). $(8.183,8.314315,8.333)$ The immediate interpretant is the intended meaning of the utterer or all that the sign is intended to mean. As such it is not really an interpretant since it is not what is actually produced by the sign. But according to Fitzgerald it deserves the name "interpretant", "because of its role as a ground for the relation between sign and interpretant."21 This is 
interesting if this is how Peirce thought of the immediate interpretant. That is, it is analogous to the immediate object in that both serve as a ground. The dynamical interpretant is the actual. interpretant produced by the sign. This is what one thinks or does when one interprets a sign. This is the interpretant which we normally talk about and which Peirce usually means when he talks about interpretants. Peirce's concept of a final interpretant is one which meshes well with his pragmatism. It is important in understanding the relation between Peirce's pragmatism and his sign theory. The final interpretant is that which would finally be decided to be the true interpretation if consideration of the matter were carried so far that an ultimate opinion were reached. The connection is this: the sign relation requires an interpretant. The interpretant is an effect of the sign. This effect is the meaning of the sign. However, it is not always the intended meaning nor is it the final or full meaning. That is, it does not always give a complete conception of its object. All thought and knowledge is by way of signs. The essential incompleteness of knowledge is at least in part due to the incompleteness of the interpretants of signs.

There is another point at which Peirce's pragmaticism can be seen as an outgrowth of his sign theory. The dynamical interpretant seems to be subdivided into an emotional, energetic and logical interpretant. 22 Briefly, the emotional interpretant is the first feeling one has at the comprehension 
of a linguistic sign or the feeling some signs, such as a musical composition or an abstract painting, may produce. (5.475) The energetic interpretant is an effect or exertion which "may be a muscular one as in the case of the command to ground arms, but it is much more usually an exertion upon the inner world, a mental effort. . ." (5.475), but 1t can never be the meaning of an intellectual concept since such a meaning is general while the energetic interpretant is a single act. The meaning of an intellectual concept and the pragmatic meaning of a statement is to be found in the logical interpretant. The logical interpretant is a sign which may produce its own interpretant. This is where it differs from the energetic and emotional interpretants which may terminate in an action or emotion.

The logical interpretant may end in what Peirce calls the ultimate logical interpretant. 23 This interpretant is a habit. A habit is a disposition to act in such and such a way under certain circumstances. A habit is a would be and so a member of thirdness. It can be expressed In conditional form. (If such and such circumstanceiarises I will react in such and such manner. ${ }^{24}$ ) The pragmatic maxim is that:

- - every theoretical judgement expressible in a sentence in the indicative mood is a confused form of thought whose only meaning, if it has any, lies in its tendency to enforce a corresponding practical maxim expressible in a conditional sentence having its apodosis in the imperative mood. $(5.18)$

The meaning of a theoretical judgement expressible in a sentence sign in the imperative mood is the ultimate 
logical interpretant of that sign which interpretant 13 a habit concerning practical action to be taken is the statement is true.

At this point we can see how Peirce's theory of signs meshes nicely with his pragmaticism. The meaning of a general concept is found in its ultimate logical interpretant which is a practical habit of action. This does not mean that every sign produces an ultimate logical interpretant or that every theoretical judgement results in an ultimate logical interpretant. The production of such an interpretant usually requires some inquiry and mental exertion on the part of the interpreter. The production of such a habit also should not be seen as the dead end of the logical interpretant chain. It is more like an indefinite resting place. The habit is subject to change for it is itself an interpretant sign. The ultimate logical interpretant should gradually approach the final interpretant. 25 That the ultimate logical interpretant must be a habit which is open to modification is made necessary by Peirce's requirement that any interpretant is itself a sign and so must be capable of producing a further interpretant. Modification of a habit by either mental or physical experimentation to determine its results might be considered the interpretant of that proviously established habit. The ultimate logical interpretant as a habit may be based on an accurate conditional statement about its effects on the world, but the theoretical requirements of Peirce's sign 
WHAT IS THE OBJECT OF A SIGN?

As we learned from earlier discussion we must distinquish between two objects: the immediate object and the dynamical object. The dynamical object is the object in itself. The immediate object is that concept or idea we have from previous aquaintance with the dynamical object. Here it will be worthwhile to go into some detail. When we ask what the object of a sign is, we must be clear about what we are asking. Firgt, we must be clear as to whether we are referring to the immediate or dynamical object. Secondly, we must be clear as to whether we mean what the object of a given sign is or what is the nature of (or what may function as) the object of signs in general. Therefore let us take these questions one at a time.

First, we will consider what the nature of the dynamical object is and what may serve as a dynamical object. Secondly, we will consider what might be the object of some specific signs, which might present problems to the doctrine that every sign has an object. Thirdly, we will consider the nature of the immediate object. Finally, we will try to show how this immediate-dynamic object distinction might be applied to bring light to some difficult passages in Peirce. 
What, then, is the nature of the dynamical object and what may serve as the dynamical object of a sign? The answer to the second part is very simply, anyhting. Anything may serve as a dynamical object. Anything that exists either independently of the mind or in imagination may be a dynamical object. Anything which may be talked about whether it is real or fictive may be a dynamical object. Peirce says this about the object of a sign:

The objects - for a sign may have any number of them - may each be a single known existing thing or a thing believed formerly to have existed or expected to exist, or a collection of such things, or a known quality, or relation or fact, which single object may be a collection, or whole of parts, or it may have some other mode of being, such as some act permitted whose being does not prevent its negation from being equally permitted, or something of a general nature desired, required, or invariably found under certain circumstances. $(2.232)$

It is clear from this passage that Peirce's concept of object is broad enough to include things from any of his categories of being and virtually anything which can be talked about. He includes relations, qualities, facts, existents, fictive beings, possible beings, thoughts, habits, laws, actuals, etc.. We should not restrict our search for the object of a specific sign to any one mode of being such as actual existents, or even to real objects as opposed to fictive objects. Anything may function as an object and it may have any mode of being.

Next we turn our attention to some specific signs to determine what their objects might be. Here the question arises as to whether every algn has an:object. There is no 
question about this for Peirce. For him every sign must have an object. This is an essential part of the sign relation. The sign always points away from itself to an object. A sign "refers to", "represents", or "stands for" something else. A sign does not always stand for something else in the sense of "standing in place of" as a variable may stand in place of a term in a symbolic sentence. The relationship of sign to object should be understood in the general sense of reference or representation. The sign refers to or points to its object. Just as we might say thought is always thought of something, a sign is always a sign of something. Perhaps it may be useful here to make the distinction which Peirce draws from the scholastics: that of a thing being in the mind actualiter and habitualiter. "A notion is in the mind 'actualiter' when it is actually conceived; it is in the mind 'habitualiter' when it can directly produce a conception." (8.18) For Peirce there are two ways a thought is in the mind or two ways a thought might be said to exist.

We might apply a similar distinction to signs. But this distinction should be made in terms of functioning (or in terms of the power of a sign to function as a sign). A sign does not have an object when it is not functioning as a sign or when it is actually being interpreted. This is similar to the point made earlier about the distinguishing feature of a sign. That is, a thing is a sign when it has the power to determine an interpretant and along with this 
the power to point to an object.

Now although a sign is said to be a sign when it has the power to refer to an object, this does not mean that it refers to one and only one object. It can refer to an object but just what particular object it will refer to depends on the context in which it actually functions. For example, the word "bird" may be said to have a range of objects to which it may potentially refer, but taken by itsolf it rofers to no object in particular. The word "bird" may refer to any particular bird given the proper context or it may refer to the class of birds or it may refer to the characteristics possessed by birds. The point is, that while it is not functioning it possess the power to refer to these objects, but it does not actually refer to any of them and it can not actually refer to any of them until it functions in some context. So it has no objects, only the power to refer to some object when it functions. For a sign to have this power or potentiality, a convention is at least a necessary condition.

Possession of this power is the fundamental basis of distinction between signs and non-signs. But signs only have an object or interpretant when they are actually exercising this power.

Signs very rarely if ever, function in isolation. When they function they are sinsigns or sign-vehicles of here and now, set in a context of other signs. Even actual thought is a sinsign. It is a thought of here and now also 
set in the context of other signs. The object of here and now sinsigns is determined by their context. For example, we are usually not concerned about the object of individual letters of the alphabet. For instance, what is the object of the letter "P"? We might want to say that it is a rule or pronounciation or a rule or package of rules about how it may function or how we may use it. Certainly the letter "P" is a sign and so it should have an object. In this context we might plausibly say that the above rule is the object of "P". 27 But the letter " $P$ " is an almost purely functional sign. That 1s, it usually has no object or meaning except as part of a larger sign, and whatever is the object of the larger sign is the object of "P". The object of "P" is determined by its context when it is used. Suppose we say that "P" is used in the word "Person". The object of " $P$ " is really not the question now. The question is, "What is the object of 'Personi?" By itself the word "Person" may have as its object the general concept of a human being. But in the larger sign, "That person is tall", Person is part of the sign "That person" which has as its object whomever the utterer means "That person" to refer to. The point of this is to indicate that looking for the object of each Individual sign may not be fruitful. If we consider the sign to be a functional entity it is best to determine its object when it is actually functioning significatively. Some signs rarely if ever have an object except in conjunction with other signs. Signs such as "the", "a", "some", and "most" 
are examples.

There is support for this view in Peirce. For example he says,

As for a noun, considering the meaning which it has in the sentence, and not as standing by itself, it is most conveniently regarded as a portion of a symbol. Thus the sentence, "every man loves a woman" is equivalent to "whatever is a man loves something that is a woman". Here "whatever" is a universal selective index, "is a man" is a symbol, "loves" is a symbol, "something that" is a particular selective index and "is a woman" is a symbol. (2.296)

We also find him discussing the symbol "loveth".

" "i let us take as an example of a symbol the "loveth" ... Now we are to understand that "loveth" occurs in a sentence; for what it may mean by itself if it means anything, is not the question. Let the sentence then, be "Ezekiel loves Huldah". Exekiel and Huldah must then be or contain indices; for without indices it is impossible to designate what one is talking about. Now the effect of the word "loveth" is that the pair of objects denoted by the pair of indices Ezekiel and Huldah is represented by the icon or the image we have in our minds of a lover and his beloved. $(2.295)$

If we were to analize this entire sign we would have to say that it is perhaps three separate objects. Obviously Ezekiel is one, Huldah is one, and not so obviously, the particular relationship of loving is the other. Taken together as one sign, "Ezekiel loves Huldah" is a sign of one object, i.e. the Ezekiel - Huldah love relationship. This type of analysis can, I think, be done for any language sign.

Every language sign or word is symbolic. As such it is a general type as pointed out earlier. If it is taken by itself it refers to a general. In the case of common nouns such as "man", "dog", "bird", "people" etc. they refer to general concepts of those types of things. But they 
may also refer to particulars simply by using them to denote any individual who possesses the properties associated with that word. In the case of indexical pronouns such as "this", "that", etc., if taken by themselves, they may be said to refer to the general concepts of thisness or thatness. But most often they are used to refer to a specific object in a given context. In the case of articles such as "a" or "the", we may say that they refer to the concepts of definiteness or indefiniteness. But again they usually attach to a noun or pronoun and take on its object. Verbs have the general concepts of the states of being or action as their references. Conjunctions and prepositions have relational concepts as their references.

All words, if considered individually, must be construed as symbols and are therefore general and as such their objects are general. But many words, especially articles, demonstrative pronouns, or prepositions are funetional sings. That is, when they are instantiated in a token of themselves, they become parts of larger signs and so the question becomes, "What is the object of the larger sign?". And in these cases the sign can be a sign of anything (fictional, actual, general, or merely possible). For instance, if I ask my wife, "Is it raining?" the object is my desire to know the state of the weather. If I say, "Unicorns elude every captor save a virgin.", this has as its object an imaginary being. Now the question may arise as to whether this sign really does refer to an object. It is quite true 
that it does not refer to a real object or real secondness, but it does nevertheless refer to an object which exists even if it only exists in the imagination. And if the context is such that the proposition is taken to refer to what people imagine about unicorns, it is a proposition about a real state of affairs, 1.e. the things people really imagine or believe about unicorns.

So far we have only considered specific words and their objects and I think we have shown that we can find a plausible object for any word. But what about other types of signs, such as those which we generally refer to as natural signs, or signs such as colors, or signs such as motions or actions. If our analysis of all signs as requiring a convention and at least to some degree symbolic is correct, then a similar explanation of their objects be possible. Once again, we must emphasis the distinction between the sign actually instantiated in a sign situation and the sign concelved as separate from any sign situation. Let us take one of Peirce's favorite examples, that of the weathervane. Any actual weathervane has as its object the wind which is blowing it at any particular instant, and more specifically the wind in respect to its direction. A particular weathervane abstracted from any situation may not have any object at all. It may just be an ornament on someone's early american-style livingroom wall. But if we want to consider the weathervane as a type of which any particular weathervane is a token, its object is not any 
actual wind but only the concept of wind direction. The same is true of qualities such as "redness". Redness, if designated as a sign of danger, is a sign of the particular danger it is alerting us to at any particular time. But again, a convention is required if a sign is to have the power to refer to its object. 28 Actions and hand motions likewise are only tokens of types which we deem significant in some respect. When I put up my hand with the palm facing out it is usually taken as meaning stop. Its object is my particular desire or expectation to have you stop at that time. That particular hand motion is just a token of a type which we have conventionally given significance. Its object taken as a type is the general idea of stopping. A particular life or action may be said to be a sign. As such it would have as its dynamical object whatever it is thought to be significant of. The object of the life of Socrates may be Socrates himself or it may be "the steadfast pursuit of truth" or it may be philosophers in general, depending on the context in which Socrates is used as a sign. We could go on, but I think that this should be sufficient to make the point. The point is this: it is usually not difficult to determine the object of a sign once it is put in a context or more specifically once it actually functions as a sign.

In the above explanations I spoke of signs as abstracted from a sign situation. But this may be misleading. Strictly speaking, I do not think we encounter any signs 
which are abstracted from a sign situation. This is where the necessarily triadic nature of a sign may become clear. A sign is not the same as the sign vehicle. A sign is a triadic relation of object - sign - vehicle - interpretant. Anything at all can be a sign-vehicle but what makes a signvehicle a sign is its power to bring an interpretant into a relation with its object. (1.542) A convention is required in order that a sign-vehicle and anything of the same type have this power. By this I mean that a convention is a necessary condition in the making of a sign, for without it the bare facts of significant resemblance or physical connection are not enough to produce the triadic connection and give the sign-vehicle the power to determine an interpretant and point to an object. Usually this convention is much more complex than just that things of such and such type will refer to such and such object and have such and such interpretant. The convention is tied to a maze of other conventions about how various types are related in various situations. Even if taken by itself, the sign is in a certain context, i.e. the context of being considered outside of an elaborate sign situation. In this context the sign may have as its object the conventions and rules about how the word is used or it may have as its object a general concept, so even in this situation it is functioning as a sign. Whenever a sign functions, it functions triadically and that means it is connecting an interpretant to an object. Without a convention this connection can not be made in a way 
adequate to produce a sign. Signs are not actual signs unless they are functioning and when they function they are necessarily triadic. When they are not functioning they have no specific object but are capable of directly pointing to one.

On the above interpretation it seems almost tautological to say all signs have an object but there is some dispute on the issue. Greenlee argues that although a sign always points away from itself, the pointing is not always to something referred to, represented or stood for. What the sign always points to, according to Greenlee, is its interpretant. His point is that not all signs are referential in the sense that proper names are and to look for an object where there is none or where the finding of one requires a stretching of the meaning of "object" beyond recognition is not useful.

This kind of stretched reasoning, according to Greenlee, is brought out in the example of tiger tracks. A hunter comes across fresh tiger tracks and interprets them as signs of a tiger in the surroundings. According to Peirce, the dynamical object is that with which the sign presupposes an acquaintance in order to convey some further information concerning it. (2.231) The dynamical object, according to Greenlee, is the tiger which made the tracks and the immediate object is the tiger as represented by the tracks interpreted by the hunter. Now, he says, change this situation so that the tracks are not of a tiger but are 
blurred so that the hunter takes them to be tracks of a tiger. The hunter is mistaken and the object he takes them to be the sign of is fictive.

Greenlee says now the immediate object is no tiger as qualified by the relation of being represented by a sign interpreted by the hunter, but is an imaginary construct in the hunter's mind, built out of past experience of tigers. And what this amounts to is that the object is the past experience as relevant to the present sign. Greenlee then says:

I suggest that Peirce's statement that the object is what there must have been previous experience of in order that the sign be significant be changed to read that the object is that relevant previous experience itself. The point of reducing the immediate object to relevant previous experience is to obtain a conception of the object of the sign which is illustrated by any signification.

Now any possible instance of signification is similar to the one just discussed insofar as experience is re-presented and provides the basis for the sign function. If one wishes, then, to preserve Peirce's language and to insist that all signs represent "objects", JustIfication for this insistance can be extracted from the argument that every sign re-presents an object because it presupposes previous experience on the part $88^{f}$ the interpreter in order to be significant to him.

The point Greenlee seems to be making is that since we are sometimes deceived by signs or because we sometimes misinterpret the actual object of a sign, that which we think is the object is not an object at all in the "normal" sense of the word object. That is, there is no real referent of the sign. There is only an interpretant which is an imaginary object produced by the sign. At best, according to Greenlee, this might be said to be an object only in that 
it requires the re-presentation of an experience which is the basis of the imagining. One would belleve this is what Greenlee means, but cannot be certain since he makes no clear statement about what he considers to be the familar sense of "refers to", "represents", "stands for" or "object".

From this example one gets the impression he means external object or object external to the mind, because in the first instance of the example the tiger really did make the track and so its immediate object according to Greenlee was the "tiger as represented by the tracks", while in the second instance in which the track was not made by a tiger but only thought to be made by a tiger, the immediate object is, according to Greenlee, "an imaginary construct in the hunter's mind". The problem here seems to be the idea which Greenlee appears to have that the immediate object in each case is different. That is, in the first case the immediate object is the "tiger as represented by the tracks interpreted by the hunter", while in the second case the immediate object is "no tiger as qualified by the relation of being represented by a sign, but an imaginary construct in the hunter's mind, built out of past experience." Just what Greenlee means by "tiger represented by the tracks" is unclear. Does he mean that it is an independently existing Higer as represented by the track" (something distinct from the independently existinf tiger who makes the track) or does he mean that it is an imaginary construct which the hunter has in his mind? If he means something like the for- 
mer, it is a rather difficult meaning to grasp. If he means something like the latter, then it would seen to be the same as the immediate object in the second instance. And this is my point. The immediate object of the track is not different in the two cases. The immediate object of the track is a mental construct in both cases.

This brings us to the question of what the nature of the immediate object is. As noted earlier, the immediate object is "the object as cognized in the sign and therefore an idea." (8.183) The immediate object is always a mental construct or idea or concept or whatever you may prefer to call it. You may call it imaginary if you do not think it has an actual parallel in the world of entities independent of our thought of them, but the actual character of the concept or construct is the same. The immediate object is an idea and so is of the nature of thought and therefore a sign, since all thought is in signs. Greenlee, then, has given a faulty analysis of this sign situation. In both cases the sign is a token of a type which the hunter has learned signifies a tiger. The blurred track is enough like the type which the hunter has determined is significant, so that he takes it to be a token of that type. The source of the sign is not important in this respect. The dynamical object is not merely that which made the sign. If this were true, then the dynamical object of every written or spoken word would be the one who spoke it or wrote it. The dynamical object of "Napolean" would be in this case Bill West since 
he just wrote the word. The dynamical object is so named because of its dynamic character. That is, the dynamical object "determines" the sign. But Peirce cautions against taking "determines" in too narrow a sense. The sign is determined through previous experience of its object by the interpreter.

The person who interprets . . any . . sign whatsoever must be determined by the object of it through collateral observation quite independently of the sign. Otherwise he would not be determined to thought of that object. $(8.178)$

Now in our example of the tiger, even though the tracks may have been made by two different animals, to the hunter both tracks are tiger tracks. The sign for him is the same and the context is the same regardless of the source of the sign, therefore the object is for him the same in both instances. The immediate object is that concept or idea of a tiger in the nearby surroundings. The dynamical object is the tiger(s) or knowledge of tiger(s) which, by collateral experience of them, determines the hunter to the thought of "tiger(s) in the nearby surroundings". The dynamical object is not the specific tiger that is in the nearby surroundings but the "tiger(s) in the nearby surroundings" of collateral experience.

On this interpretation the immediate object may be difficult to distinguish from the interpretant. And this type of analysis may be close to Greenlee's claim that the interpretant is what is referred to in many sign situations. 30 But I think this interpretation is more along the lines of 
what Peirce intended when he spoke of objects. It does not eliminate a dynamical object from the sign situation as does Greenlee's analysis, and I think the dynamical object can not be eliminated. And it certainly does not eliminate the immediate object.

I must admit, however, that we are still left with a thorny problem in our example of the tiger. The above analysis of this sign situation has left out the actual tiger who really made the track in the first instance (not to mention the other actual animal who made the blurred track in the second instance). That is, he is not the object (dynamical or immediate) of the sign. He can not be the dynamical object because there is no collateral experience of this particular tiger by the hunter, and he can not be the immediate object because the immediate object is an idea not a particular individual. The problem is that it seems quite natural to say that the object of the footprint is the actual tiger who made the footprint. Wouldn't this be an excellent example of an indexical sign, with a real connection with its object? But I think that to say this is to transcend the sign situation as the hunter experiences it, and in doing this we change the context of the sign and so its object. I do not think it is implausible to say that the actual tiger is not the object of the tracksign from the hunter's perspective. Certainly the hunter knows that if the track was made by an actual tiger thon there must be an actual tiger in the nearby surroundings, 
but this is not to say that, that actual tiger is the object of the track-sign. I think it is more proper to say that the object is the general concept of an actual tiger in the nearby surroundings.

When we change the situation and transcend it by saying that in one instance an actual tiger made the track and in the other actual animal (not a tiger) made the track mistaken asa tiger track, we have essentially assumed a collateral experience of the actual objects and so they become the dynamical objects which are determining us to thought of these objects. (8.178) The hunter has no such experience and so both signs, being tokens of one type to him, have the same dynamical and immediate objects although this in no way changes the reality of the connection between the signs and actual objects which produced them. If he were to find after further tracking that it was an unusually heavy fox which made the blurred track which he mistook for. a tiger track, then this fox would become the object of the track-sign, because the sign situation has now been changed by this new collateral information.

At this point we come to the distinction between the intended object and meaning of a sign, and the interpreted object and meaning of a sign. The reason for this discrepancy is precisely the difference in the context of the sign for the sign user or utterer and the sign interpreter. The object intended and the object interpreted are often just not the same. This is because signs are functional 
entities and how they function depends greatly on the context of the sign and this context is to some extent always dependent on the interpreter or utterer.

I would now like to enter a brief discussion of a question which is much debated. I stated earlier that everything can function as a sign but not everything is a sign. There is much dispute on this issue. The question relates to our discussion of the immediate and dynamic object and to the general question of the object of signs. I believe that the immediate-dynamic distinction of objects may be helpful in resolving the issue although I doubt it will resolve it completely.

While there are many passages which suggest that Peirce may have held that everything is a sign, he nowhere makes an explicit statement to this effect, at least not to my knowledge. For instance in 1.339 Peirce says that the object of a representation is nothing but a representation of which the first representation is the interpretant. This, according to Peirce, leads to an infinite regress of objects which are themselves representations of a former object. In 1.538 (1903) Peirce says that every sign stands for an object independent of itself but that it can only be a sign of that object insofar as that object is itself of the nature of a thought or of a sign. Peirce even speaks of man as being nothing more than a sign. $(5.251)^{31}$ And in $7.408 \mathrm{fn} .19$, Peirce says, "James wants us to say 'things'. I reply that 'ideas' were always meant as objects, direct objects, not 
matters of psychology, by those who talked of them." Ideas are of course, signs. Passages such as these might lead one to suspect that Peirce felt everything is a sign. If the object of every representation is itself of the nature of a representation, idea or sign and if even man is nothing more than the word or sign man uses, then it must seem that indeed everything is a sign. This is something like the approach of Fairbanks in "Peirce on Man as a Language: A Textual Interpretation". 32 Ransdell argues that for Peirce everything is a sign in "Another Interpretation of Peirce's Semiotic". He believes that for Peirce there is nothing in the world and nothing thinkable at all which does not incorporate the relational structure of intelligibility which is the structure of the sign relation. Brock takes a simllar point of view in his "Draft of a Critique of Greenlee's Peirce's Concept of a Sign". 33

But even in the passages mentioned above Peirce leaves some doubt. In 1.339 he says that the endless series of representation as objects may be conceived as having an absolute object at its limits. And in $7.408 \mathrm{fn} .19$ he talks of the "real external things" eventhough he says they are beyond the power of thought.

I would like to suggest that in these passages and others like them, Peirce is referring to the immediate object. If this is the case, then there is no need to conclude that everything is a sign. Every sign has an immediate object and the immediate object is of the nature of an idea 
and therefore it is a sign. So although everything has a sign as its object it may only be as the immediate object. This leaves the possibility that the dynamic object may be of a different nature although 1t, too, may be a sign. That we must leave room for things other than signs seems clear from Peirce's categorial division. Peirce insists on dividing things ontologically according to whether they are firsts, seconds or thirds. Now signs are assigned only to the category of thirdness. And although there may be degenerate forms of thirdness, they are first or seconds of thirdness and are not in the categories of firstness or secondness. So there are things thinkable which are not thirds and therefore not signs. It is one thing to say that all thought is in signs, which Peirce clearly held. It is quite another thing to say that everything thought about is a sign, which it is not at all clear Peirce held. 


\section{CONCLUSION}

This study of Peirce's semiotic theory has concentrated on two main questions. They are the questions of the conventionality and intentionality of signs. On the question of conventionality I have tried to show that every sign is to some extent conventional. By this I mean that some designation must be made by some intelligence that such and such will signify such and such. It is quite true that there are many things which are easily designated as signs for other things because of some real physical connection between them, or some natural resemblance or similarity between them. But these connections do not adequately constitute a sign situation. In such cases a mental separation of options is required and a decision must be made as to what will constitute the ground of the sign and what exactly it will refer to among the options available. That which separates signs from non-signs is the power to point to or refer to an object. Anything may function as a sign but it will not be able to function as a sign until it acquires the power to refer to an object. A sign before it acquires the power can become a sign of anything. The convention designates the range of a sign when it makes the mental connection between sign and object. This is why a 
convention is required for signification. I tried to show that in an iconic sign relation a convention is required in order to specify what characteristics were to be regarded as significant. In an indexical sign situation I tried to show that a convention is required in order to restrict the range of potential objects since there usually is more than one physical connection between the sign in question and objects in the world. In all cases an intellect must perceive the physical connection and then decide that one of the two connected events will be a sign of the other. 34 On the question of intentionality I argued, as Peirce did, that every sign indeed has an object but only when it actually functions as a sign. In this regard I laid much emphasis on context in the theory of sign. Here I tried to point out that it is not difficult to identify the object of a sign when the sign is actually functioning, and that signs really have no object until they are in an actually functioning sign situation.

It is at this point that sign theory seems to be the most complex. When Peirce discusses objects of specific signs he most often uses propositions as examples. These are complex signs in that they are made up of various individual signs starting with the smallest mark on a piece of paper and moving through letters, words, phrases and clauses. Every sign is in a similar situation, that is, every sign is found in a context of other signs and that context is essential in determining the object of a given 
sign. A sign-vehicle usually if not always, has more than one potential object within the range of objects specified by the conventions concerning that sign-vehicle, and it is the context of a sign which determines the specific range. This is why we must wait until a sign is actually functioning in order to determine its specific object and this is also why, as Peirce says, a sign may have any number of objects. (2.232)

But there are still some questions about the conventionality and intentionality of signs which may be worthy of some investigation. For one, we may wonder if at least actual objects of secondness are signs which require no convention since when they are perceived they produce a thought, and since every thought is a sign. They produce this thought without a convention. Are not actual objects that are capable of being perceived therefore signs since they are capable of producing an interpretant in the form of a thoughsign? It may be that these are examples of signs which require no convention. But the problem is that they do not refer to any object, unless one wants to posit a thing-initself. And for peirce a sign must refer to an object in order to be a sign. It seems that the production of thoughtsigns by actual objects, if this is indeed what is involved in perception, is a dyadic relation and therefore not a sign situation.

At this point we can see a connection between the intentionality and conventionaltty of signs. If, as Greenlee 
argues, we redefine the sign situation to require only an interpretant (i.e. to omit the requirement of intentionality) then actual objects that are capable of being perceived would have to be considered to be both signs, and signs requiring no convention. Thus it may be that Greenlee's non-intentional definition of signs and his requirement of conventionality are incompatible. :

Another consequence of the conventional nature of signs is the necessary generality it brings to signs. Peirce has placed signs in the category of thirdness which is the category of generals. Thought, too, according to Peirce is general. It is the conventions of thought which extend the power to refer to objects and the power to determine interpretants to "things". This is a necessary condi, tion in making these "things" signs. And it is this convention of thought which gives the sign its essential generality.

This thesis has concentrated on an interpretation of Peirce's semiotic in regard to conventionality and intentionality, but there are of course many other relevant issues in regard to these question, which will require much further study. For instance, can semiotics be naturalized and fit into a behavioral theory of psychology? Do we necessarily hypostatize certain non-real entities by making them the objects of signs? If signs are at least to some degree conventional and mind dependent and if all thought is in signs, how much objectivity can there be in communica- 
tion about the world? Just what is the relation between the "real world" (if there is one) and our signs concerning it and what do we count as knowledge of it? Can a single definition account for all kinds of signs or must we develop a theory of signs which associates signs through various family resemblances? If semiotic theory is a theory of meaning can it account for all kinds of meaning such as the meaning of life or the meaning of an abstract painting or an emotional piece of music?

These are some of the broader questions all of which require much difficult work. But there is also a maze of narrower technical questions of detail which constantly crop up in semiotic discussion. Many of these may have to be tackled before we can advance to the broader questions. I have attempted a start on two of the more important problems by using Peirce and to a lesser degree Greenlee, to bring them under scruting. There is much room for discussion and refinement. 


\section{NOTES}

1 I am putting aside the question of self reference. Although it is an interesting point, whether or not there are signs which refer to themselves fully as their complete object won't effect the answer to the question of whether all signs have an object. If there are such self referential signs, we would simply say that they have themselves a objects.

2 Douglas Greenlee, Peirce's Concept of Sign (The Hague: Mouton \& Co., 1973), p. 37 .

3 I have not discussed the various degenerate forms of the caregories. For instance, thirdness has a firstness of thirdness and a secondness of thirdness which can also be further divided into degenerate cases of these subcategories. Again, although interesting, this is not essential to a discussion of Peirce's semiotic. For a more detailed discussion see $1.284-1.353$ and $1.417-1.530$.

4 Greenlee makes much of this distinction and feels that it is the source of some confusion on the part of Peirce. He argues that Peirce was not always aware of this distinction himself and at times this lead him astray in his conclusions about signs. See Douglas Greenlee's Peirce's Concept of Sign (The Hague: Mouton \& Co., 1973), pp. 8-4, 40-42, 134-135 and Sec. III, Chap. 2. Also "Peirce's Hypostatic and Factorial Categories" by Douglas Greenlee, Transactions of the Charles S. Peirce Society IV (1968), pp. 49-50.

5 For a detailed discussion of the 66 classes see "On Peirce's 66 Signs" by Gary Sanders, Transaction of the Charles S. Peirce Society VI (1970), pp. 3-16.

6 Douglas Greenlee, Peirce's Concept of Sign (The Hague: Mouton \& Co., 1973), p. 43 .

7 Douglas Greenlee, Peirce's Concept of Sign (The Hague: Mouton \& Co., 1973), pp. 133-137.

8 Douglas Greenlee, Peirce's Concept of Sign (The Hague: Mouton \& Co., 1973), pp. 70-84. 
9 Douglas Greenlee, Peirce's Concept of Sign (The Hague: Mouton \& Co., 1973), p. 77.

10 Mental association may also be construed as determination by a law of nature. This type of interpretation would be indicative of the attempt of many to maturalize the sign structure and integrate it with behaviorist psychology.

11 I realize that there are many who would deny that not everything is a sign, and perhaps even Peirce held this. I will deal briefly with this issue toward the end of the thesis (pp. 57-59).

12 The reason this is not a sign situation is that it is a simple cause effect relation and so can not be a sign situation, since the sign is a triadic rather than dyadic relation. This is not to say that there are no physical interpretants. Certainly there are.

13 One is tempted also to bring out the parallels between the essential intentiality of thought and the basic relationof sign to object or basic intentionality of signs. (5.253 in Peirce) Like Brentano, for Peirce, thought is always thought of something. This follows from the doctrine that a sign is always a sign of something.

14 Much of the following has been taken from Greenlee's discussion of the Index in Pelrce's Concept of Sign (The Hague: Mouton \& Co., 1973), pp. 84-93. He gives a lucid explaination of the index and demonstrates its dependence on a convention.

15 Thomas Goudge also notes this type of deterioration in his article "Peirce's Index". Transactions of the Charles S. Pelrce Society I (1965) pp. 52-70. He also notes some other problems with Peirce's Index and Symbol.

16 This is the ground of an object which we discussed earlier. The sign stands for its object not in all respects but in reference to a sort of idea which Peirce sometimes calls a ground. (2.228)

17 Douglas Greenlee, Peirce's Concept of Sign (The Hague: Mouton \& Co., 1973), p. 89.

18 Ex. The word "man"lis a general mode of succession of three sounds or representamens of sounds, which becomes a sign only in the fact that a habit, or acquired law, will cause replicas of it to be interpreted as meaning a man or men." (2.292)

19 Fitzgerald makes this point well using Icon, Index and Symbol, but it may be made within the division of Rheme, 
Dicisign and Argument.

20 See 2.276 and 2.306 in Peirce. Also John J. Fitzgerald, Peirce's Theory of Signs as Foundation for Pragmatism (The Hague: Mouton \& Co., 1966), pp. 52,58 and 66 .

21 John J. Fitzgerald, Peirce's Theory of Signs as Foundation for Pragmatism (The Hague: Mouton \& Co., 1966), p. 77 .

22 This interpretation of the emotional, energetic and logical interpretants as subdivisions of the dynamical interpretant is developed by Fitzgerald in Peirce's Theory of Signs as Foundation for Pragmatism (The Hague: Mouton \&c Co., 1966), pp. 76-90. It differs from Weiss and Burk, Goudge, Buchler and Feibleman who identify the emotional, energetic and logical interpretant with the immediate, dynamic and final interpretant respectively. Fitzgerald's interpretation seems to be the better one. It distinguishes between the ultimate logical interpretant and the final interpretant which do seem to be different in Peirce.

23 The reason I say the logical interpretant may end in an ultimate logical interpretant is that for Peirce not every sign continues its progression to its logical completion. In 2.303 he says, "If the series of successive interpretants comes to an end, the sign is thereby rendered imperfect at least." The interpretant chain may be broken of $f$ by a distraction or a person may not exert the necassary mental effort to develop an ultimate logical interpretant and develop a habit. Some signs may only have energetic or emotional interpretants so that the progression toward an ultimate logical interpretant may not even get started.

24 This does not necessarily imply physical reaction. It may only be a mental reaction.

25 For a complete discussion of this connection see Fitzgerald's Peirce's Theory of Signs as Foundation for Pragmatism (The Hague: Mouton \& Co., 1966), Esp. Chaps. IV and VIII.

26 Peirce in 1.542 says that the triadic sign relation must "consist in a power of the representamen to determine some interpretant to being a representamen of the same object."

27 It may seem that I am stretching the meaning of "object" here, but I don't think it is implausible to answer the question, "What does 'P' refer to?", by saying that by itself, as a letter in isolation, its only reference may be the package of rules about how "P" may function. This is one of the objects to which "P" may potentially refer. And in the context described above it does not seem to stretch the meaning of "object" as I take $t$ t or as I think Peirce takes it. 
28 Let me stress here that I do not intend to say that there are not some things that by their close physical connection or their characteristic resemblance to some object are more likely to become signs of that object. I only mean that they can not become significative of that object unless there is some designation by a mind that that thing shall be a sign of that object.

29 Douglas Greenlee, Peirce's Concept of Sign (The Hague: Mouton \& Co., 1973), pp. 67-68.

30 Ransdell makes a similar point to the effect that the sign relation Greenlee describes may not be much different from Peirce's in Ransdell's article "Another Interpretation of Peirce's Semiotic" Transactions of the Charles S. Peirce Society XII (1976), pp. 97-110. He also argues for the necessity of, at least, the immediate object, but rejects the idea of a "real object" because "there is semiosis which does not concern itself with reality." This of course, is true according to Peirce, but Peirce does not identify the real object with the dynamical object (see 8.314), and Ransdell fails to make this" distinction himself in the body of his paper. Instead, he seems to identify the real and dynamical object and then dismisses them with the above offhand remark.

31 See Matthew J. Fairbanks' article on this subject; "Peirce on Man as a Language: A Textual Interpretation", Transactions of the Charles S. Peirce Society XII (1976), pp. 18-32.

32 "Peirce on Man as a Language: A Textual Interpretation" by Matthew J. Fairbanks in Transactions of the Charles $S$. Peirce Society XII (1976), pp. 18-32.

33 "Another Interpretation of Peirce's Semiotic" by Joseph Ransdell in Transactions of the Charles S. Peirce Society XII (1976), pp. 97-110.and "Draft of a Critique of Greenlee's Peirce's Concept of Sign by Jarrett E. Brock in Transactions of the Charles S. Peirce Society XII (1976), pp. 111-126.

34 Whether or not such a decision is forced on the intellect once the connection is perceived may be an interesting and pertinent topic of investigation. 


\section{BIBLIOGRAPHY}

Books

Augustine, St. Aurelius. Concerning the Teacher ard on the Immortality of the Soul (New York/London: D. AppletonCentury Co., 1938).

Bernstein, Richard J. (ed.). Perspectives on Peirce (New Haven/London: Yale Univ. Press, 1965).

Boler, John F. C. S. Peirce and Sckolastic Realism (Seattle: Univ. of Wash. Press, 1963).

Burks, Arthur W. (ed.). Collected Papers of Charles Sanders Peirce Vol. 7-8 (Cambridge: Belnap Press of Harvard Univ., 1966).

Davis, William H. Peirce's Epistemology (The Hague: Martinos Nijhoff, 1972).

Feibleman, James K. An Introduction to the Philo'sophy of C. S. Peirce (Cambridge/London: The M. I. T. Press, 1970).

Fitzgerald, John J. Peirc's Theory of Signs as Foundation for Pragmatism (The Hague: Mouton Press, 1966).

Greenlee, D. Peirce's Concept of Sign (The Hague: Mouton Press, 1973).

Hartshorne, C., Weiss, P. (eds.). Collected Papers of Charles Sanders Peirce Vol. 1-6 (Cambridge: Belnap Press of Harvard Univ., 1965).

Maritain, Jacques. Ransoming the Time (New York: Charles Scribner's Sons, 1941).

Moore, Edward Co., Robin, Richard S. (eds.). Studies in the Philosophy of C.S. Peirce (Amherst: Univ. of Mass. Press, 1964).

Morris, Charles. The Pragmatic Movement in American Philosophy (New York: George Braziller Inc., 1970).

Potter, Vincent G., S. J. Charles S. Peirce on Norms and Ideals (Worcester: Univ. of Mass. Press, 1957).

wiener, Philip. C. S. Peirce: Selected Writing (Values in a Universe of Chance) (New York: Dover Pub. Inc., 1958). 
Wiener, Philip P., Young, Frederic H. Studies in the Philosophy of Charles Sanders Peirce (Cambridge: Harvard Univ. Press, 1952).

\section{Journal Articles}

Brock, Jarrett E. "Draft of a Critique of Greenlee's Peirce's Concept of Sign", Transactions of the Charles S. Peirce Society, Sprimg, 1976, Vol. XII, No. 2

Dewey, J. "Peirce's Theory of Linguistic Signs: Thought and Meaning", Journal of Philosophy, Feb. 141945

Fairbanks, Matthew J. "Peirce on Man as a Language: A Textual Interpretation", Transactions of the Charles S. Peirce Society, Winter, 1976, Vol. XII, No. 1

Fitzgerald, John J. "Ambiguity in Peirce's Theory of Signs", Transactions of the Charles S. Peirce Society, Spring, 1976, Vol. XII, No. 2

Goudge, T. A. "Further Reflexion on Peirc's Doctrine of the Given", Journal of Philosophy, May 21, 1936

Goudge, T. A. "Peirce's Index", Transactions of the Charles S. Peirce Society, Fall, 1965, Bol. I. No. 2

Greenlee, Douglas. "Peirce's Concept of Sign: Further Reflections", Transactions of the Charles S. Peirce Society, Spring, 1976, Vol. XII, No. 2

Nagel, E. "Peirce's Guesses at the Riddle", Journal of Philosophy, July 6, 1933

Ransdell, Joseph. "Another Interpretation of Peirce's Semiotic". Transactions of the Charles S. Peirce Society, Spring, 1976, Vol. XII. No. 2

Reese, William L. "Peirce on Abstraction", Review of Metaphysics, June 1961

Sanders, Gary. "Peirce's Sixty-six Signs", Transactions of the Charles S. Peirce Society, Winter, 1970, Vol. VI, No. 1

Thompson, Manley H., Jr. "Logical Paradoxes and Peirce's Semiotic", Journal of Philosophy, Aug. 18, 1949

Weiss. P. "Peirce's 66 Signs", Journal of Philosophy, July 5,1945 